\title{
Passenger lymphocyte syndrome after minor ABO-incompatible stem cell transplantation: A case report
}

\author{
Zhiyuan Xu ${ }^{1}$, Xiaofei Li ${ }^{1}$, Kai Liu ${ }^{1}$, Ye Zhang ${ }^{1}$, Guangyan Zhuang ${ }^{1}$, Tingting Liu ${ }^{1}$, \\ Tianhong Miao', YuShiang Lin ${ }^{2 *}$ \\ ${ }^{1}$ Blood Group Lab, Beijing Red Cross Blood Center, Beijing 100088, China; \\ ${ }^{2}$ Nobel Prize Winner Erwin Neher Research Institute, Jiangsu Zhongji Wantai Biological Pharmaceutical Co., Ltd. Jiangyin, Jiangsu \\ 214400, China.
}

Keywords: stem cell transplantation, $\mathrm{ABO}$ discrepancy, passenger lymphocyte syndrome, transfusion

\section{INTRODUCTION}

Passenger lymphocyte syndrome (PLS) is a complication of organ transplantation or stem cell transplantation in which donor B lymphocytes or plasma cells produce alloantibodies against recipient red blood cell (RBC) antigens, leading to the development of haemolytic ane$\mathrm{mia}^{[1-2]}$. Although PLS is a self-limiting disease, it affects the success and survival rate of transplantation due to the occurrence of haemolytic disease, disseminated intravascular coagulation, and organ failur $\mathrm{e}^{[3-4]}$. Present studies have demonstrated that PLS occurs in individuals after liver, renal, or cardiac transplantation, but only a few studies reported that PLS occurs in individuals who undergo minor $\mathrm{ABO}-$ incompatible stem cell transplantation. In our study, serological ABO, Rh typing, and direct coombs test were used to identify a better strategy to administer blood transfusion in a patient with PLS.

\section{CASE REPORT}

A 14-year-old boy was diagnosed with type II mucopolysaccharidoses and received stem cell transplantation. The patient's blood type was A, of the CcDEe

*Correspondence to: Yushiang Lin, Nobel Prize Winner Erwin Neher Research Institute, Jiangsu Zhongji Wantai Biological Pharmaceutical Co., Ltd. Jiangyin, Jiangsu 214400, China. E-mail: 1448639963@qq.com. Conflict of interests: The authors have declared no conflict of interests. phenotype, and the donor's blood type was $\mathrm{O}$, of the $\mathrm{CcDEe}$ phenotype. The patient had intermittent fever, with the highest body temperature $\left(38.2{ }^{\circ} \mathrm{C}\right)$ noted on day 5 after stem cell transplantation. On day 7 , the occult blood test showed black-coloured stools (2+) and a rash was noted on the patient's chest and back. Type $\mathrm{O}$ washed RBCs were given on day 6 , and $\mathrm{AB}+$ apheresis with radiation treatment was given on day 9 . All whole blood specimens containing ethylene diamine tetraacetic acid(EDTA) were analyzed on day 6, 9, and 10 .

Serological ABO forward typing (anti-A, anti-B, Immucor Inc., USA), ABO reverse typing (ABO typing cells, Shanghai Blood Tech, China) and a chloroform elution test was performed to analyze the patient's red blood cells to identify the presence of anti-A or anti$\mathrm{B}$ antibodies produced by donor lymphocytes, and the eluted solution was incubated with A cells, B cells, and screen cells. Capillary tube centrifugation was performed to separate the patient's own aged RBCs at the end of the capillary tube and donor's RBCs from the stem cells in the middle of the capillary tube.

After stem cell transplantation, anti-A alloantibodies were noted in the patient's plasma, and the agglutinin titres became elevated within days (Table 1). On day 6 , the haemoglobin level declined to $55 \mathrm{~g} / \mathrm{L}$, and the serological anti-A and anti-Al typing showed mixfield appearance (before transfusion), as the specimen was mixed with the stem cells from the donor's blood. The same results were observed on days 9 and 10 as the 
A case report, 2018, 2(3)

Table $1 \mathrm{ABO}$ serological result in the patient

\begin{tabular}{cccccccccc}
\hline Collected date & anti-A & anti-B & anti-H & anti-Al & A cell & B cell & O cell & Auto-control \\
\hline Day 6 & $4+\mathrm{mf}$ Less free cells & 0 & $\mathrm{~W}+$ & $4+\mathrm{mf}$ Less free cells & 0 & $3+$ & 0 & 0 & \\
Day 9 & $4+\mathrm{mf}$ & 0 & $\mathrm{~W}+$ & $4+\mathrm{mf}$ & $\mathrm{W}+$ & $4+$ & 0 & $\mathrm{~W}+$ & 0 \\
Day 10 & $4+\mathrm{mf}$ & 0 & $\mathrm{~W}+$ & $4+\mathrm{mf}$ & $1+\mathrm{s}$ & $4+$ & 0 & $1+$ \\
\hline
\end{tabular}

$\mathrm{mf}$ : mix field, 0 : negative, $\mathrm{W}+$ : weak positive.

specimen was mixed with the donor's RBCs.

The blood sample on day 6 after capillary tube centrifugation demonstrated $\mathrm{CcDEe}$ after Rh typing $(\mathrm{Rh}$ typing card, Jiangsu Libio Biotech CO. Ltd, China) of the patient's own aged RBCs (from the end of the capillary tube) and CcDEe after Rh typing of the donor's RBCs from the donor's stem cells (from the middle of the capillary tube). The results of the patient's Rh typing on day 6, 9, and 10 are shown in Table 2.

Table $2 \mathrm{Rh}$ serological result in the patient

\begin{tabular}{cccccc}
\hline Collected date & anti-C & anti-c & anti-D & anti-E & anti-e \\
\hline Day 6 & $4+$ & $4+$ & $4+$ & $4+$ dcp & $4+$ \\
Day 9 & $4+$ & $4+$ dcp & $4+$ & $4+$ dcp & $4+$ \\
Day 10 & $4+$ & $4+$ dcp & $4+$ & $4+$ dcp & $4+$ \\
\hline
\end{tabular}

dcp: double cell population.
All samples demonstrated negative results on antibody screening tests (Screen cells, Sanquin, Switzerland) and on the LISS-coomb test (Anti-IgG, C3d gel column test, BioRad, USA). However, reverse/forward typing showed an elevation in A-cell agglutinin levels on day 6 . The results of the patient's direct antiglobulin (coombs) test (DAT) and eluted test are shown in Table 3. Type $\mathrm{O}$ washed red blood cells were transfused after stem cell transplantation, and the haemoglobin level elevated to $73 \mathrm{~g} / \mathrm{L}$ on the day 7 without transfusion reaction.

\section{DISCUSSION}

PLS is a kind of post-transplantation hemolytic disease. Organ transplantations such as liver, renal and

Table 3 IAT, DAT and eluted test in the patient

\begin{tabular}{|c|c|c|c|c|c|c|c|c|}
\hline \multirow{2}{*}{ Collected date } & \multicolumn{2}{|c|}{ IAT } & \multicolumn{2}{|c|}{ DAT } & \multicolumn{4}{|c|}{ Eluted test } \\
\hline & Screen cell & A cell & anti-IgG & anti-C3d & Control & A cell & B cell & O cell \\
\hline Day 6 & 0 & 0 & W+ & 0 & 0 & 0 & \pm & 0 \\
\hline Day 9 & 0 & \pm & $\mathrm{W}+$ & $\mathrm{W}+$ & 0 & & \pm & 0 \\
\hline Day 10 & 0 & $2+$ & $2+$ & $2+$ & 0 & $\mathrm{~W}+$ & \pm & 0 \\
\hline
\end{tabular}

cardiac transplantation occur frequently in contrast to stem cell transplantation. PLS shows high association with B lymphocyte count from donors due to the antibody formation rate corresponding to B lymphocyte causing a higher immune response level.

Classifying PLS from hemolytic disease is a challenge. The first specimen in our study was from day 6 , from which this retrospective and perspective investigation to confirm the PLS was conducted. Free RBCs from the mix field of serological forward anti-A, anti$\mathrm{Al}$, anti-c and anti-E tests elevated with date due to donor's stem cell hemostasis RBCs and extra RBC products transfusion.

The features of PLS are: (1) PLS occurs in various blood groups and occurs easily in ABO incompatible transplantations, especially in minor-incompatible. The case in our study is a blood type A recipient who received blood type $\mathrm{O}$ donor's stem cells. Published studies have demonstrated the incidence of PLS to be $44 \%$ in recipients with blood type $\mathrm{A}$ and $18 \%$ in recipients with blood type $\mathrm{B}$, which may be explained by the average of A antigens count being more than that of B antigens $^{[5-7]}$. (2) In general, PLS presents from day 7 to day 14 post transplantation which relates to B lympho- cyte physiology. The published study reported PLS in $\mathrm{ABO}$ over the course of 3 months in contrast to PLS in $\mathrm{Rh}$ for 1 year $^{[1]}$. (3) Clinical symptoms in PLS: hemoglobin level continuously declines, while total bilirubin level becomes elevated. Active bleeding does not present in patients. The case in our study presented elevated anemia, uremia and bilirubin. (4) The DAT for PLS reports a reaction to anti-IgG or anti-C3d or mixed anti$\mathrm{C} 3 \mathrm{~d}$ and anti-IgG. The eluted solution from the case showed anti-A, B with anti-IgG agglutinin in DAT at day 6; and anti-A and anti-A, B with stronger both anti-C3d and anti-IgG agglutinin in DAT at day 9.

There is no precision therapy for PLS, and steroids are generally used to suppress the immune response to blood transfusion for oxygen metabolism support ${ }^{[8-10]}$. Type $\mathrm{O}$ washed $\mathrm{RBCs}$ is preferable to instead of ABOmatched transplantation due to unexpected anti-A or anti-B. The case in our study was major incompatible with A washed RBCs and major compatible with $\mathrm{O}$ washed RBCs.

PLS is a temporary disease, showing a huge association with the recipient's immune response and drug treatment. The symptoms release with the destruction of the donor's lymphocyte. DAT is a sensitive and di- 
rective tool to screen PLS and identify the level of seriousness for the clinical symptoms. Our study suggests DAT should be added in routine test for transplantation procedures to monitor the antibody sensitized RBCs before and after transplantation. Meanwhile, blood transfusion staffs are recommended to make important responses to the diagnosis of PLS by keeping up to date with progress relating to post transplantation PLS research and practices.

\section{References}

[1] de Bruijn S, Philipse E, Couttenye MM, et al. Passenger lymphocyte syndrome (PLS): A single-center retrospective analysis of minor ABO-incompatible liver transplants. J Clin Transl Hepatol, 2017, 5(1): 9-15.

[2] Brunetta DM, Albuquerque LM, Batista AHM, et al. Passenger lymphocyte syndrome in liver transplantation. Rev Bras Hematol Hemoter, 2017, 39(4): 364-7.

[3] Sandler SG, Han S, Langeberg A, et al. Nonhemolytic passenger lymphocyte syndrome. Transfusion, 2017, 57(12): 2942-5.

[4] Ahrens N, Hutchinson JA. Passenger leucocyte syndrome. Transplantation, 2016, 100(9): 1787-8.
[5] Schlitt HJ, Radddatz G, Steinhoff G, et al. Passenger lymphocytes in human liver allografts and their potential role after transplantation. Transplantation, 1993, 56(10): 9515 .

[6] Nadarajah L, Ashman N, Thuraisingham R, et al. Literature review of passenger lymphocyte syndrome following renal transplantation and two case reports. Am J Transplant, 2013, 13(6): 1594-600.

[7] Ramsey G. Red cell antibodies arising from solid organ transplants. Transfusion, 1991, 31:71-86.

[8] Foell D, Glasmeyer S, Senninger N, et al. Successful management of passenger lymphocyte syndrome in an ABO-compatible, nonidentical isolated bowel transplant: a case report and review of the literature. Transfusion, 2017, 57(6):1396-400.

[9] ElAnsary M, Hanna MO, Saadi G. Passenger lymphocyte syndrome in $\mathrm{ABO}$ and Rhesus D minor mismatched liver and kidney transplantation: A prospective analysis. Hum Immunol, 2015, 76(6): 447-52.

[10] Gniadek TJ, McGonigle AM, Shirey RS. A rare, potentially life-threatening presentation of passenger lymphocyte syndrome. Transfusion, 2017, 57(5):1262-6.

(Received 27 July 2018, Revised 17 August 2018, Accepted 21 August 2018) 


\section{Antibody}

安迪溥拮

\section{JiangSu LIBO Medicine Biotechnology Co.,Ltd.}

\section{Diagnosis of Hemolytic Disease of the Newborn}

\section{ABO、Rh(D) Antigen Testing Card Newborn}
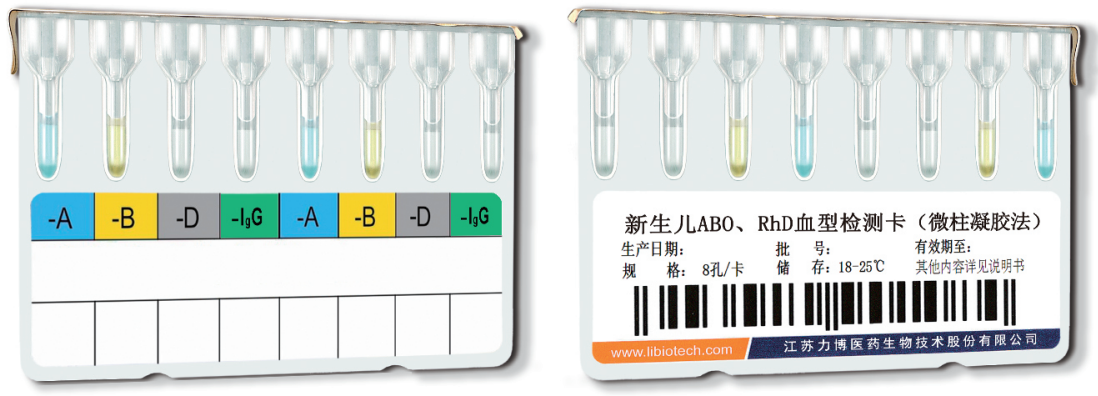

Intended Use :

The product is suitable for clinical tests on $\mathrm{ABO}$ and $\mathrm{Rh}(\mathrm{D})$ blood typing and direct antiglobulin test (DAT) for newborns and suspected hemolytic disease patients. It is only applicable for clinical test, but not for blood screening.

\section{Case :}
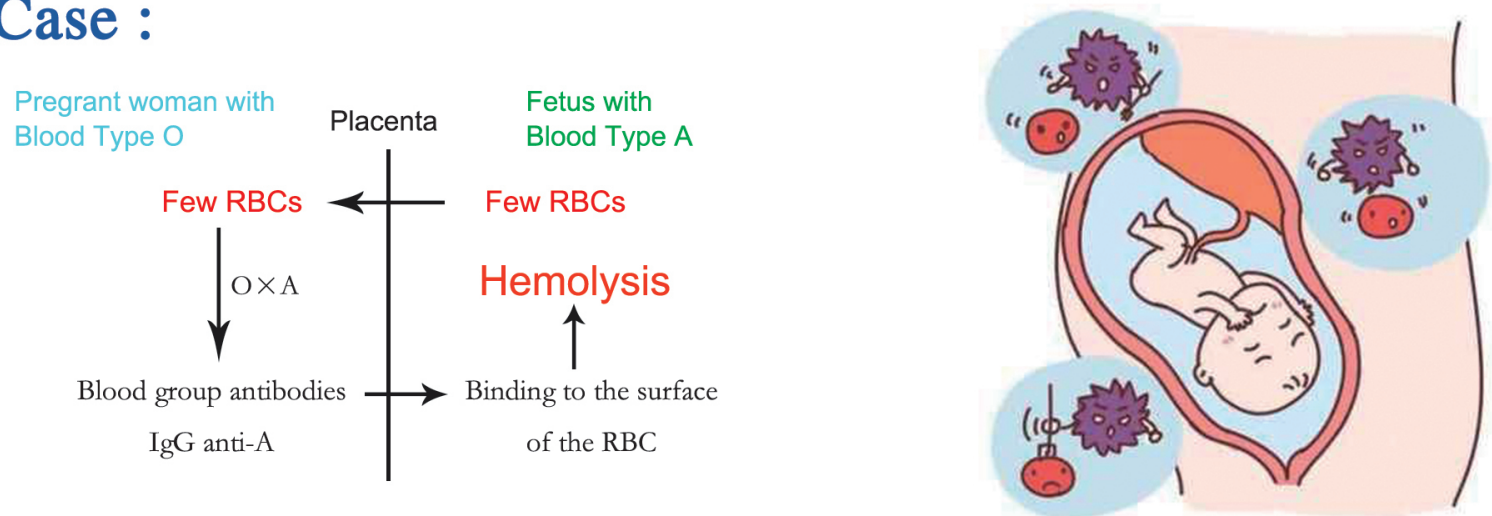

\section{Antibodl 安画溥君 \\ JiangSu LIBO Medicine Biotechnology Co.,Ltd.}

Address: No 78 West Dongsheng Road, Jiangyin, Jiangsu214400, P.R. China

Web Site: www.libiotech.com

Sales Tel: +86-510-86990618、+86-510-86990633

Tech Tel: +86-510-86990608、+86-510-86990655

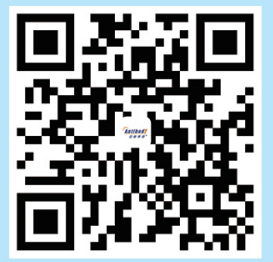

